\section{FDA approves Alzheimer's drug against the recommendation of its scientific panel. Be very concerned.}

\author{
Joshua Freeman, MD
}

Originally published in the Medicine and Social Justice blog, https://medicinesocialjustice.blogspot.com/2021/06/fdaapproves-alzheimers-drug-against.html

Early in June, an article in the NY Times discussed the possible approval of aducanumab, a recombinant DNA (the “-ab” is always clue!) drug intended to treat Alzheimer's disease. The FDA approved the drug a few days later, going against the recommendations of its advisory committee of scientific experts, and generating this "Quotation of the Day" in the Times from one of its members, G. Caleb Alexander: "There's no way to recover the opportunity to understand whether or not the product really works in the post-approval setting." Almost immediately, three members of the advisory committee, Joel Perlmutter of Mayo, David Knopman of Washington University in St. Louis, and Aaron Kesselheim of Harvard, resigned in protest of the decision. Dr. Kesselman, along with his colleague, Dr. Jerry Avorn, presents a strong indictment of the FDA in an OpEd guest essay in the Times, and they are not alone. Most neurologists, including those who I know are experts on and leading researchers in Alzheimer's, echo these concerns.

This is pretty unusual. Not just the resignations, but the reason for them - the decision by the FDA to approve a new drug based on evidence of effectiveness so weak that the scientific advisory panel recommended against it. It raises a number of questions, the foremost one of which is "why?" Also: Is this a precedent, and will it happen again, or more regularly? What was the reason that the advisory committee recommended against approval? Who were the people at the FDA who overruled them, and what were their reasons?

First let's start with cui bono? - who benefits. This is certainly Biogen, the company that developed aducanumab and will market it, under the tradename Aduhelm. It is estimated that it will cost $\$ 56,000$ a year. This is not a record; there are other recombinant DNA drugs - including several for neurologic conditions - that cost even more. In fact, as indicated in a recent study by the American Academy of Neurology, "Medicare paid 50\% more for neurology drugs over 5 years while claims rose only $8 \%$ ". Still, it is a tidy chunk of change, and since Alzheimer's is a far more common disease than most of the rare ones that are ostensibly treated by more expensive drugs, Biogen expects to make a bundle. And, because only the very very rich could afford this much, most of it will be paid by you. That is, by insurance companies that collect your premiums, and especially by Medicare, the insurer for the majority of Alzheimer's patients, which is funded by your tax dollars. This is described in another article, with the subhead: Despite scant evidence that it works, the drug, Aduhelm, is predicted to generate billions of dollars in revenue, much of it from Medicare.' If people are not insured, or rich, they can forget it. Which, in this case, might be just as well.

Making a lot of money, as much as they possibly can wring out of patients and insurers, is the core business of pharmaceutical companies (and most companies, although pharmaceutical companies have been particularly good at making outrageous profits, always ranking as the \#l industry for profit). It is not, despite their ads, (and they spend much more on marketing than on research and development) about improving your health. You are just the coincident vehicle for generating their profits. Their drugs do not have to actually help you get better; as long as they don't harm you too much - and, of course, as long as the FDA approves them - they are golden. This is why they spend so much on marketing, and lobbying, and specifically lobbying the FDA. Indeed, the "golden parachute" of many FDA staffers is to retire from the agency and get a job lobbying for a drug company. Sigh. So that one is obvious. Corrupt and despicable, yes, worthy of complete anger and condemnation, yes. But obvious. Not, heretofore, however, predictable.

There is another stakeholder group involved, Alzheimer's advocacy groups. The FDA still has an acting chief, Janet Woodcock, and another article notes these groups supported her becoming permanent. It says, "Woodcock's nomination back in February when the application for the drug, aducanumab by Biogen, was pending, its approval was a sign that they backed the right candidate." Wow. Shouldn't we be paying them attention? After all, they are not the drug manufacturers who will be making a mint. And Alzheimer's is a terrible disease, and we need effective treatments, right?

Not so fast. Yes, Alzheimer's is a terrible disease. Those who have it suffer greatly, at least until it is so advanced they no longer recognize what is going on. And their loved ones continue to suffer, more and more. A drug that would cure it, or mitigate it, or make it progress more slowly would be wonderful (although it shouldn’t cost $\$ 56,000$ a year!). But 
is aducanumab that drug? Not according to the scientific panel, who know. But the advocacy groups are pushing for it anyway. Why? Well, they make not be making most of the money, but they have to justify their existence. And they almost certainly are getting donations from those drug makers. And maybe, even, they care so deeply about the disease that their hope and optimism overcomes appropriate caution. It wouldn't be the first time that this has happened (e.g., the continued promotion by breast cancer advocacy groups for decreasing the age and increasing the frequency of screening even when science showed the opposite).

It also wouldn't be the first time that those advocating for victims of terrible disease pushed strongly for approval before studies were completed. One meaningful and important example is the efforts of groups such as ACTUP to get early approval for anti-retroviral drugs, as people were dying in droves from AIDS. But there are differences. One is the disease; Alzheimer's is not killing people quickly as did AIDS, and no one is claiming that aducanumab or any other drug will change its eventual downhill course. Another is health equity. In the political and social landscape of the 1980 s, AIDS was a disease primarily affecting gay men and IV drug users, definitely not the mainstream. Leaders such as Ronald Reagan refused to offer support. And, perhaps most importantly, the anti-retrovirals were showing a definite positive effect in studies, and the calls were to speed up the approval process. In the current case, the trials are complete and the evidence showing a positive effect is not sufficient.

This is in no small part due to the fact that the "positive effect" studies show involves changes in biomarkers, not changes in people's lives. That is, they look at lab tests rather than whether people die less soon or suffer less. Yes, there is evidence, as there is evidence in many diseases, that these intermediate markers are related to long-term outcomes, but the problem is that the further out they get the more it becomes like a game of "telephone" (well, our drug affects $\mathrm{A}$, and $\mathrm{A}$ is related to $\mathrm{B}$, and $\mathrm{B}$ may be related to long-term outcomes). We need studies that look at patient-oriented not disease-oriented or laboratory-test-oriented effects.

Sometimes an intermediate marker improves but the patient does not, or gets worse. It could be from a side effect of the drug (drug safety) but it can also be from the desired positive effect of the drug! For a time, diabetes groups pushed to lower the target hemoglobin Alc (HbAlc) -- a measure of long-term glucose level, to be 5 rather than 6 , because people with diabetes with lower HbAlc levels had lower levels of diabetes complications. Makes sense. But when the average blood sugar over several months is lower, it increases the risk of significant hypoglycemia (low blood sugar), which can be more dangerous than higher sugar. Indeed, if you pass out from low blood sugar, fall and break your hip, and die, the lower rate of complications from your diabetes in the long term is irrelevant. There is an old medical joke about Harvard doctors being very insistent that their residents keep patients' lab values in the normal range, so that even when the patient died, they died in "perfect Harvard balance”.

This is not what we want. We want diseases to be cured or ameliorated; for lives to be lengthened and improved in quality. We certainly do not want drug companies to make billions off of people's suffering. When the FDA approves a drug over the recommendations of its scientific panel, it should be of great concern to all of us.

Don't forget cui bono? 